\title{
Blockchain-based medical and water waste management conception
}

\author{
M. Kassou ${ }^{1, *}, S$. Bourekkadi $^{2,3}, S$. Khoulji $^{1}, K$. Slimani $^{2,3}, H$. Chikri $^{1,3}, M . L$. Kerkeb $^{1}$ \\ ${ }^{1}$ ERISI, National School of Applied Sciences, Abdelmalek Esaadi Universiy, Tetouan, Morocco. \\ ${ }^{2}$ Ibn Tofail University, Kenitra, Morocco \\ ${ }^{3}$ EuRSED, Vienne, France \\ http://orcid.org/0000-0001-8036-2260, http://orcid.org/0000-0001-5264-2599
}

\begin{abstract}
The revolutionary technology blockchain began with cryptocurrencies like bitcoin but has since expanded beyond the worlds of finance and banking. One relatively unexplored application domain is medical and water waste. The production of medical/water waste is an integral part of healthcare operations. However, Health care and water waste management methods can also pose a health and environment risk if the various steps in the management process are not carried out correctly. The objective of this paper is to propose conception of a system, based on the Blockchain and IoT, that ensures the control of these wastes in order to effectively manage, coordinate and monitor their disposal. An initial design of this system and an evaluation of the system's performance are also presented.
\end{abstract}

\section{Introduction}

Blockchain technology involves the application of cryptography and the consensus mechanism. Private key encryption has been used in the Blockchain to meet authentication requirements (such as copyright and ownership) (Kosba et al., 2016). In addition, cryptography reduces the vulnerability of hacked personal information. To communicate authenticated information, a distributed peer-to-peer (P2P) network is required. The distributed network rather than a centralized network was chosen because there is no single point of failure. The consensus mechanism is the final requirement, which governs the entire transaction process such as record keeping. It is an essential element of the Blockchain, which is responsible for the verification and validation of the recorded information. The verification of transactions and blocks is performed by nodes called miners (i.e. validators) using consensus algorithms; these miners are responsible for extracting new blocks. There are several consensus algorithms available, such as proof of work, proof of concept, proof of issue and proof of identity (Cachin, n.d.). In addition, for the exchange of information between two entities, an agreement is written, which is simply a set of rules known as an intelligent contract whose purpose is to execute and complete a transaction based on the given set of rules (Christidis and Devetsikiotis, 2016b).

The Blockchain is still in its infancy and could have a much broader impact than cryptography. Namely on the healthcare sector, where it may have the potential to transform the healthcare system, placing the patient at the center of the healthcare ecosystem and increasing the security, privacy and interoperability of health data. Thus, accelerating the development of other solutions in the sector such as "medical waste and waste water management ".

Much of the waste generated in the sanitary sector is considered hazardous waste. The health and environmental risks caused by this waste can be well defined, and its treatment must be clearly separated from the treatment of waste generated in other areas.

Problems arising from the mismanagement of medical waste include damage to humans from sharp instruments, diseases transmitted to humans by infectious agents, and contamination of the environment by toxic and hazardous chemicals. According to the United Nations World Health Organization (WHO) position paper, the mismanagement of medical waste (primarily the use of contaminated needles and syringes) has caused the following number of contaminations around the world: Hepatitis B: 21 million contaminations; Hepatitis C: 2 million contaminations; and AIDS: 260,000 contaminations. The above figures show how important proper treatment of medical waste is. According to the WHO guideline, hazardous waste should be treated as close as possible to where it is generated. The risks involved in transporting hazardous waste are significant, and the risk factor inherent in certain materials (e.g. contamination) increases day by day. In the current global context of industrial development, managing medical waste effectively is becoming an increasingly important concern for the entire international community("Poor Medical Waste Management (MWM) Practices and Its Risks to Human Health and the Environment: A Literature Review,” 2013). 
The long-term objective of this paper is to develop a system based on Blockchain technology and the Internet of Things to effectively manage, coordinate and monitor the disposal of these wastes. Firstly, the different categories of hospital waste will be defined, and secondly, the traditional methods of collection and disposal of this waste will be presented. Next, we will detail the benefits of implementing the Blockchain and the Internet of Things that promise to address this problem. Finally, we will present our proposed design for the medical/water waste management system.

\section{Problem Identification and Motivation}

The solid waste management process can be divided into two parts: 1. Collection and transportation 2. Disposal and recycling. The World Bank describes waste management as the collection of solid waste from the point of generation to the point of treatment or disposal. In developed countries, most existing waste management systems include several third-party waste collectors who transport waste disposed of in garbage cans to a recycling plant or landfill. In developed countries, the main cost of the waste management system is spent on waste disposal. In the case of developing countries, the reverse is true. Most of the waste management budget is spent on waste collection and only a small fraction is spent on waste disposal (Odonkor and Mahami, 2020). A 2019 European Union report reveals that more than 2503 million tonnes of waste were generated in that year by households and other economic activities. Nearly $47 \%$ of this waste was incinerated, 36\% was recycled (excluding energy recovery), $10.2 \%$ was landfilled and the remainder was incinerated to recover energy. Conversely, in most Asian countries, most of the waste was sent to open landfills and was not treated. In countries such as Nepal, Bangladesh, India, Thailand and Vietnam, more than $60 \%$ of the waste was landfilled or untreated. Japan and Singapore incinerated most of their waste, while only Hong Kong recycled more than $40 \%$ of its waste.

\subsection{The various types of hospital waste}

Hospital waste is a very vast subject, hence the existence of differences in the names and classifications of this waste from one country to another, but it does not affect the essential content. Indeed, in Australia, HW is called medical waste, controlled waste, clinical waste. In Japan, it is called infectious waste (WHO, Regional Office for the Western Pacific, 2015). For classification, some also use the term infectious/hazardous, for hazardous waste they represent $10-20 \% ; 15 \%$ are infectious and pathological waste, while the remaining $5 \%$ are divided into PCT sharps waste $(1 \%)$, chemical/pharmaceutical waste $(3 \%)$ and less than $1 \%$ are special waste such as radioactive and cytotoxic waste. In some countries such as Austria, the term "infectious waste" is used for waste generated by patients carrying limited contagious diseases (black plague, anthrax, tuberculosis, etc.), while in Greece all waste generated by patients is considered infectious. According to the Ministry of Health, Population and
Hospital Reform (MSPRH), 2015 instructions, hospital waste is classified as follows:

- Non-hazardous waste: can be assimilated to household waste (DAOM)

- Hazardous waste: can be infectious, chemical and toxic, radioactive and mechanical.

According to the MSPRH, 2015 instructions, hospital waste is classified as follows:

- Non-hazardous waste: can be assimilated to household waste (DAOM)

- Hazardous waste: can be at risk of infection, chemical and toxic, radioactive and mechanical hazards.

\subsection{Health Risks of Hospital Waste}

The management of HW (Hospital Waste) has become a critical issue, it is also of increased importance because of the potential environmental and public health risks that can even lead to epidemics (WHO).

All persons who come into contact with hazardous waste directly by handling the waste or indirectly through inappropriate management of HW are potentially at risk ("Poor Medical Waste Management (MWM) Practices and Its Risks to Human Health and the Environment: A Literature Review," 2013). The main group: doctors, nurses, laboratory technicians, pharmacists, stretcherbearers, hospital health of people at risk are: - The medical professionals and maintenance staff, health auxiliaries, scientific staff. - Internal or external patients receiving treatment in health facilities and their visitors. - Support service workers related to health care facilities such as: laundry services, waste handling and transportation services, cleaners, waste handlers, transporters, maintenance staff. - Workers in waste disposal facilities, including garbage collectors. - The general public and, more specifically, children playing with objects they may find in waste outside of health facilities.

\subsection{Risks of hospital waste on the environment}

From an environmental point of view, the hospital is a large consumer of water, in fact, compared to the consumption in a domestic environment, where the average consumption per inhabitant per day is 150 to 200 liters, for hospitals the average value increases from 400 to 1200 liters per day and per bed (Health at a Glance: Europe 2018 state of health in the EU cycle).

In addition to this consumption of public water, special water used by the hospital (sterile water, for example) is also added to this consumption. Consequently, if the volumes of water entering the hospital are large, the volumes discharged into the public sewerage system are also large; these discharges can generate environmental pollution. The toxic risk is theoretically real (Kasuku et al., 2016), both for the environment and for Public Health, due to possible pollution by heavy metals (mercury, silver, chromium, nickel, cobalt...) and by organic molecules (solvents, antibiotics, disinfectants, detergents, drugs...). These soluble products therefore represent a danger of water pollution since they can modify the physico-chemical 
characteristics of the water and harm the proper functioning of the treatment plant by destroying its purifying flora (Sriyono, 2020).

According to a UNESCO report, more than $80 \%$ of hospital wastewater worldwide is not treated at all and is freely discharged into the environment. In addition, untreated wastewater discharged by hospitals in underdeveloped countries accounts for more than $95 \%$. Statistics specific to wastewater management are unclear due to inaccurate or missing information provided by industries around the world. However, consolidated information, such as data provided by the European Union, indicates that wastewater production is poorly managed. The toxic risk from drug discharges is still undetermined because very few studies have looked at the fate of drugs after disposal in the environment.

\subsection{The potential impact of the Blockchain on the Internet of Things}

The Blockchain is an immutable register of blocks. All transactions are recorded in blocks, and each block is linked to other blocks by hash functions, which are the building blocks of the block chain. A hash function considers an input of any length and produces an output of fixed length. In the book, each record is a hash that is generated from the current rent record and the last hash. This process makes each record dependent on the previous record. When the record in the book reaches a certain level, it is converted to a block (Crosby, 2016). A complete set of blocks is called a blockchain. This ledger file is not stored in a central entity server but is distributed worldwide via a network of private computers called nodes (miners) of the block chain. Each node contains a complete copy of the block chain. During a transaction, a message is broadcast to each node for approval to verify its validity. Once each node has verified a transaction, there is an electronic vote because some nodes may agree that the transaction is valid while others may consider it fraudulent. If the majority of the nodes agree that the transaction is valid, then the blocking chain is updated. If an attacker wants to change the entries, the remaining nodes will prevent this change because they have the original hash (Zheng et al., 2017). In a Blockchain approach, the register is therefore distributed, synchronized and duplicated, thus offering the same consistent, up-to-date and secure view to all participants of the network. A strong point of the blockchain is the smart contract, which is an autonomous application of the blockchain with the aim of making a contract forgeryproof and guaranteeing the absolute execution of the terms and conditions of the contract without any human intervention being necessary(Christidis and Devetsikiotis, 2016b). This is one of the key features of smart contracts; disintermediation. In other words, as soon as a user makes a commitment, it is registered within the contract. Once all the commitments have been determined, the contract is automatically applied, taking over the obligations and penalties.

In the object internet sector, the needs are strong both in terms of data security(AL-mawee, n.d.), history associated with a connected object and interoperability. Its decentralized organization and without intermediary could also allow an object to communicate with another object that could lead to certain autonomous decisionmaking by the latter. Upstream, the properties of the code will delimit the barriers and capacities of the objects to make decisions.

In terms of data security, the challenge is high in view of the sensitive and critical data that could transit through Smart Cities or connected healthcare solutions. The blockchain, which already secures Bitcoin transactions, could add a layer of security by adding a 'string' associated with the identity of the connected object(Zhang and Wen, 2017). Thus, this "identification chain" will allow objects to interact with each other without having to communicate via a third party (such as a cloud platform), thus limiting the output of information or potential attacks from outside.

\section{Result}

\subsection{Blockchain-Based medical and water waste Management architecture}

In this section, we present a system to improve the situation of hospital waste management. Our conception is based on blockchain technology combined with IoT, developed using smart contracts. Bringing government agencies and stakeholders on the same blockchain platform will lead to improved monitoring and higher transparency in the process.

\subsection{Our system stakeholders}

Coordination is one of the key functions of management, the objective of our system is to ensure for all stakeholders and responsibilities, a conjunction of efforts, a transparency of data in view of the common goal (medical and water waste management).

\subsection{The architecture of our model}

Figure 1 is a proposed model of a medical and water waste management system with a Blockchain infrastructure, in which the water treatment phase is equipped with intelligent objects based on the IoT that are capable of detecting, monitoring, treating, collecting and communicating information about the quantity of water consumed, the quantity of wastewater produced and the quality of wastewater after treatment. This allows the various stakeholders mentioned in table 1 to have realtime monitoring.

For hospital waste management, the containers of the different types of waste are equipped with intelligent objects based on the IoT that are able to measure (quantity generated), monitor, trace and share information between the different entities. The collected data will be transferred to our Blockchain via available communication technologies (e.g. WiFi, 4G and 5G) for real-time processing, real-time decision making, data 
aggregation and temporary storage of data blocks for a predefined period of time. Aggregated Data Blocks are verified by a consensus algorithm (DPoS) using the other edge nodes. The delegated issue proof consensus algorithm (DPoS) was developed by Daniel Larimer in 2014. BitShares, Steem, Ark and Lisk are among the crypto-money projects that use the DPoS consensus algorithm (Baliga, 2017).

Table 1. Stakeholders of the system

\begin{tabular}{ll} 
Stakeholders & \multicolumn{1}{c}{ Missions } \\
\hline The Director & $\begin{array}{l}\text { Responsible for the external consequences } \\
\text { of the establishment's activity. This is } \\
\text { particularly true in terms of waste water } \\
\text { disposal as it reaches the collective network }\end{array}$
\end{tabular}
and the treatment plant.

The Economic Manages the problem of solid hospital

Services

Department

\section{waste, particularly that which is}

recovered after the pre-treatments or treatments mentioned in the previous paragraphs.

Regulatory: - Contracts signed with specialized companies for: - The recovery of laboratory waste.

The maintenance (cleaning...) of the internal network. - The recovery of products with a long radioactive half-life (> 71 days).

\begin{tabular}{|c|c|}
\hline $\begin{array}{l}\text { Financial } \\
\text { Services } \\
\text { Department }\end{array}$ & $\begin{array}{l}\text { Pay: - The sanitation fee to the city, town } \\
\text { or urban community. - The pollution } \\
\text { charge and the abstraction charge to the } \\
\text { Water Agency. } \\
\text { Cash: - The amount of revenue from the } \\
\text { sale of silver salts. }\end{array}$ \\
\hline $\begin{array}{l}\text { Technical } \\
\text { Services } \\
\text { Department }\end{array}$ & $\begin{array}{l}\text { It develops and maintains network plans. - } \\
\text { It carries out or commissions work on the } \\
\text { network. - It is in charge of monitoring the } \\
\text { storage tanks for dangerous and } \\
\text { radioactive products, enabling a sufficient } \\
\text { reduction to be reached for products with } \\
\text { a short period of time (< to } 74 \mathrm{KBq} / \mathrm{Kg} \text { or } \\
2 \text { microcuries / Kg) before discharge into } \\
\text { the public network. - It prepares the } \\
\text { application files for authorization or } \\
\text { declaration of classified installations. - It is } \\
\text { in charge of the safety of the } \\
\text { establishment, as such it keeps an updated } \\
\text { file of the dangerous products stored on } \\
\text { the site. }\end{array}$ \\
\hline H.S.W.C.C & $\begin{array}{l}\text { Health, Safety and Working Conditions } \\
\text { Committee }\end{array}$ \\
\hline C.F.N.I. & $\begin{array}{l}\text { Committee for the Fight against } \\
\text { Nosocomial Infections }\end{array}$ \\
\hline C.T.E. & $\begin{array}{l}\text { Responsible of certain documents } \\
\text { including the report on the improvement of } \\
\text { working conditions drawn up by the }\end{array}$ \\
\hline C.M.E. & $\begin{array}{l}\text { Establishment Medical Commission Made } \\
\text { up of doctors, this body may issue } \\
\text { opinions on health and safety matters. }\end{array}$ \\
\hline $\begin{array}{l}\text { The eruption } \\
\text { station and } \\
\text { specialized } \\
\text { companies }\end{array}$ & $\begin{array}{l}\text { The depollution of waste water } \\
\text { Collection, recycling and disposal of } \\
\text { hospital waste }\end{array}$ \\
\hline
\end{tabular}

A DPoS-based blockchain is created with a voting system where stakeholders outsource their work to a third party. In other words, they can vote for a few delegates who will secure the network on their behalf. Delegates can also be called witnesses and are responsible for reaching consensus when generating and validating new blocks. Therefore, the DPoS algorithm creates a voting system that is directly dependent on the reputation of the delegates. If an elected node misbehaves or does not function efficiently, it will be quickly expelled and replaced by another. In terms of performance, DPoS blockchains are more flexible because they are able to process more transactions per second (TPS), compared to PoW and PoS. And finally, the verified blocks will be added to the Blockchain and then the data transfer is carried out through smart contracts that work with an IF/THEN condition system (if/when). In other words, it works as follows: IF condition A is met, THEN B must be executed. In fact, the intelligent contract will play the role of the trusted third party that was present before its invention to confirm the application of the said contract, thus making it possible to do without the latter. The computer program will automatically carry out the instructions in the contract as soon as the conditions are met (Idelberger et al., 2016).

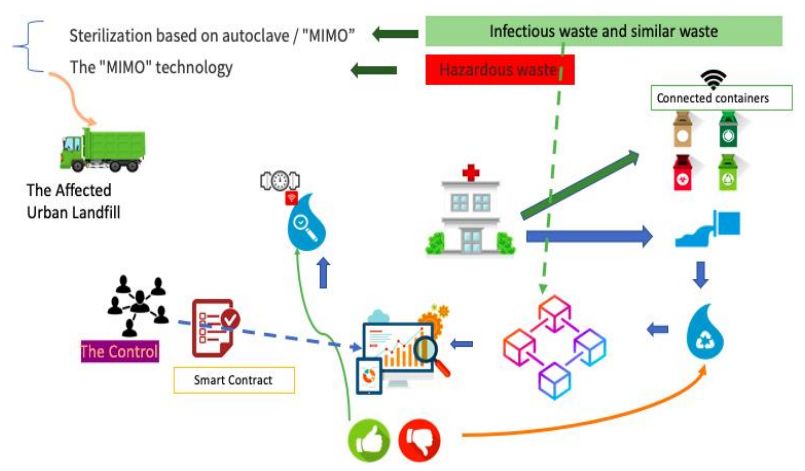

Figure 1. Blockchain-Based Medical and Water Waste Management Conception

\section{Discussion}

The objective of our proposition is to limit the nuisances and risks related to medical and water waste dangerous, fermentable or bulky nature, which would cause health or environmental impacts.

All stakeholders in our system (e.g. government agencies, environmental monitoring agencies, service providers) are involved in waste and wastewater monitoring and management by accessing and querying the data stored in the Blockchain, making appropriate (e.g.) urban landfill assignments through smart contracts; i.e. they will be able to access and view the data for which they have authorization.

- Smart IoT devices (sensors, actuators) will be installed on water monitoring equipment used by the hospital, on leather and textile waste containers and on personnel related equipment (e.g. flowmeter, water meter, storage tank, intelligent scale).

- The installed IoT devices will be able to detect, treat and collect the amount of stored water, water/waste consumption and wastewater generated and treated by the 
plant, and communicate the collected information to the peripheral nodes using appropriate communication technologies such as $4 \mathrm{G}, 5 \mathrm{G}$ and WIFI.

- The peripheral nodes will then group the collected information into data blocks, which will be temporarily stored and added to the block chain after the verification process. In addition, the edge nodes will process the collected information for real-time analysis and decision making.

- Additionally, they'll be answerable for verifying the information blocks, and every node will receive an incentive to verify and extract a new block. These incentives (digital coins) is exchanged for various benefits, as an example, they will be accustomed obtain discounts on various government services and payments (e.g., utility bills, taxes). The incentives are then introduced into the system to motivate stakeholders to adopt and participate within the system.

- For future management and higher cognitive process, a form on the platform will provide extensive services for processing and analyzing the stored data.

- Finally, various monitoring and management applications may be developed to investigate the quantity of water consumed, hazardous waste generated and therefore the number of toxic chemical liquids produced, treated and disposed of a number of the most advantages of this model include:

Real-time monitoring and forecasting of the amount of water consumed and wastewater discharged, and its quality after treatment.

Assigning a particular area to every entity as a landfill. Charging and imposing fines or prohibitions on hospitals that do not treat wastewater or discharge its waste without treatment.

In addition, to scale back environmental impacts, government agencies and environmental organizations can take effective and timely countermeasure.

\section{Conclusion}

The Blockchain technology enables new ways of organizing activities, ensuring traceability, reducing the costs and time associated with intermediaries, and strengthening confidence in an ecosystem of stakeholders. In this study, the benefits of Blockchain technology for monitoring and management of medical waste and wastewater were presented. An architecture based on the IoT and the Blockchain is proposed to monitor hospital waste by different stakeholders, such as government agencies, international environmental and health protection agencies, and to protect the environment from the adverse effects of this type of waste. This type of integrated inner hospital and water waste information system gives a analytic approach of waste data handling; it assists hospital's complex waste flow system and presents an overall view of hospital waste management performance. Also, it will be used as a tool where assessments of performance of waste management may be set and in line with the results positive modification and alterations could also be adopted so as to attain the dedicated targets and quality standards defined by world Health and Environment organizations.

\section{References}

1. AL-mawee, W., n.d. Privacy and Security Issues in IoT Healthcare Applications for the Disabled Users a Survey 57.

2. Baliga, D.A., 2017. Understanding Blockchain Consensus Models 14.

3. Cachin, C., n.d. Architecture of the Hyperledger Blockchain Fabric 4.

4. Christidis, K., Devetsikiotis, M., 2016a. Blockchains and Smart Contracts for the Internet of Things. IEEE Access 4, 2292-2303. https://doi.org/10.1109/ACCESS.2016.2566339

5. Christidis, K., Devetsikiotis, M., 2016b. Blockchains and Smart Contracts for the Internet of Things. IEEE Access 4, 2292-2303. https://doi.org/10.1109/ACCESS.2016.2566339

6. Crosby, M., 2016. BlockChain Technology: Beyond Bitcoin 16.

7. Idelberger, F., Governatori, G., Riveret, R., Sartor, G., 2016. Evaluation of Logic-Based Smart Contracts for Blockchain Systems, in: Alferes, J.J., Bertossi, L., Governatori, G., Fodor, P., Roman, D. (Eds.), Rule Technologies. Research, Tools, and Applications. Springer International Publishing, Cham, pp. 167-183. https://doi.org/10.1007/978-3-319-42019-6_11

8. Kasuku, W., Bouland, C., Brouwer, Ch.D., Mareschal, B., Mulaji, C., Malumba, M., Monama, O., Epumba, B., Kitambala, A., 2016. Etude de l'impact sanitaire et environnemental des déchets hospitaliers dans 4 éblissements hospitaliers de Kinshasa en RDC. Déchets Sci. Tech. https://doi.org/10.4267/dechets-sciencestechniques.3357

9. Kosba, A., Miller, A., Shi, E., Wen, Z., Papamanthou, C., 2016. Hawk: The Blockchain Model of Cryptography and Privacy-Preserving Smart Contracts, in: 2016 IEEE Symposium on Security and Privacy (SP). Presented at the 2016 IEEE Symposium on Security and Privacy (SP), IEEE, San Jose, CA, pp. 839-858. https://doi.org/10.1109/SP.2016.55

10. Odonkor, S.T., Mahami, T., 2020. Healthcare waste management in Ghanaian hospitals: Associated public health and environmental challenges. Waste Manag. Res. 38, 831-839. https://doi.org/10.1177/0734242X20914748

11. Poor Medical Waste Management (MWM) Practices and Its Risks to Human Health and the Environment: A Literature Review, 2013. 7, 9.

12. Sriyono, E., 2020. Digitizing water management: Toward the innovative use of blockchain technologies to address sustainability. Cogent Eng. 7, 1769366. https://doi.org/10.1080/23311916.2020.1769366

13. Zhang, Y., Wen, J., 2017. The IoT electric business model: Using blockchain technology for the internet of 
things. Peer--Peer Netw. Appl. 10, 983-994. https://doi.org/10.1007/s12083-016-0456-1

14. Zheng, Z., Xie, S., Dai, H., Chen, X., Wang, H., 2017. An Overview of Blockchain Technology: Architecture, Consensus, and Future Trends, in: 2017 IEEE International Congress on Big Data (BigData Congress). Presented at the 2017 IEEE International Congress on Big Data (BigData Congress), IEEE, Honolulu, HI, USA, pp. 557-564. https://doi.org/10.1109/BigDataCongress.2017.85 